\title{
Web-GIS tools for climate change adaptation planning in cities
}

Link to publication record in Manchester Research Explorer

\section{Citation for published version (APA):}

Kingston, R., Cavan, G., Butlin, T., Gill, S., \& Lindley, S. (2014). Web-GIS tools for climate change adaptation planning in cities. In Handbook of Climate Change Adaptation: Climate Change Adaptation Technologies Springer Nature.

\section{Published in:}

Handbook of Climate Change Adaptation

\section{Citing this paper}

Please note that where the full-text provided on Manchester Research Explorer is the Author Accepted Manuscript or Proof version this may differ from the final Published version. If citing, it is advised that you check and use the publisher's definitive version.

\section{General rights}

Copyright and moral rights for the publications made accessible in the Research Explorer are retained by the authors and/or other copyright owners and it is a condition of accessing publications that users recognise and abide by the legal requirements associated with these rights.

\section{Takedown policy}

If you believe that this document breaches copyright please refer to the University of Manchester's Takedown Procedures [http://man.ac.uk/04Y6Bo] or contact uml.scholarlycommunications@manchester.ac.uk providing relevant details, so we can investigate your claim.

\section{OPEN ACCESS}




\title{
Web-GIS Tools for Climate Change Adaptation Planning in Cities
}

\author{
Gina Cavan $^{\mathrm{a}, \mathrm{b} *}$, Tom Butlin ${ }^{\mathrm{c}}$, Susannah Gill ${ }^{\mathrm{b}, \mathrm{c}}$, Richard Kingston ${ }^{\mathrm{b}}$ and Sarah Lindley ${ }^{\mathrm{b}}$ \\ ${ }^{a}$ School of Science and the Environment, Manchester Metropolitan University, Manchester, UK \\ ${ }^{\mathrm{b}}$ School of Environment, Education and Development, The University of Manchester, Manchester, UK \\ ${ }^{\mathrm{c}}$ The Mersey Forest, Warrington, UK
}

\begin{abstract}
This chapter explores the state of the art in existing climate change risk, vulnerability, and adaptation assessment tools, with a focus on web-based tools. It then details the development and application of two online decision support tools created for climate change adaptation planning in cities - a Risk and Vulnerability Assessment Tool and Surface Temperature and Runoff (STAR) Tools. Both are freely available web-GIS tools that can be used to inform policy, strategy, and development. The Risk and Vulnerability Assessment Tool, developed through a collaborative and iterative process, follows the principles of an online public participation GIS. The Assessment Tool delivers GIS data and analysis functions online, widening the possibilities for participation in climate change adaptation planning. The STAR Tools enable assessment of the impacts of climate change on temperature and runoff in a specified urban area and evaluate the potential of green infrastructure as a climate change adaptation response. The STAR Tools can be used to develop "what if" scenarios, to illustrate how changes resulting from different land surface cover and climate change scenarios can impact upon local surface temperatures and runoff. The chapter presents the lessons learned from the development and application of these tools in municipalities across Europe and discusses key challenges for developing such tools to aid effective climate change adaptation planning in cities.
\end{abstract}

\section{Keywords}

Climate change adaptation; Urban areas; Climate resilience; Vulnerability; Risk assessment; PPGIS; Web-GIS

\section{Introduction}

Climate change, causing temperatures and sea levels to rise and an increase in the frequency and intensity of extreme events such as heat waves, droughts, heavy rainfall, and storm, presents risks to human and natural systems (IPCC 2014). The IPCC assessment reports confirm that climate change should be addressed by both mitigating the greenhouse gas emissions that are causing global warming and adapting societies to a new climate context to enhance resilience to current and future climate hazards (IPCC 2013, 2014). While mitigation actions have been acknowledged as essential for some time, adaptation has more recently emerged as a central area in climate change research, in country-level planning, and in the implementation of climate change strategies (IPCC 2014).

\footnotetext{
*Email: g.cavan@mmu.ac.uk
} 
Since around $50 \%$ of the world's population is now urban and with further growth anticipated within cities in developing countries, increasing concern is being raised about the potential impacts of climate change on urban environments and their growing populations and valuable assets. The assessment of climate change risk can help with improving the resilience of urban areas to present climate hazards in addition to providing information to guide adaptation strategies necessary for reducing future risks associated with climate change impacts.

Risk can be conceptualized through a framework comprising hazard, vulnerability, and exposure (Crichton 2001). Thus, the assessment of climate change risks can be undertaken through detailed understanding the three components - hazard, vulnerability, and exposure - where:

- Hazard is defined as the extent, severity, and probability of the climatic hazard of interest (such as a heat wave or flood event).

- Exposure refers to the degree to which elements at risk (such as people or infrastructure) may come into contact with the hazard of interest.

- Vulnerability is defined as the susceptibility to damage of the elements at risk (such as people or infrastructure) to a particular hazard at a particular intensity (as determined by the degree of exposure which could occur) (Lindley et al. 2006).

Risk assessment with the use of the hazard-exposure-vulnerability framework is useful because it enables consideration of the inherent vulnerability of elements at risk such as infrastructure or populations, rather than focusing on impacts only (Lindley et al. 2006). Identifying where vulnerability is high is central to targeting locations which require climate change adaptation strategies. Adaptation strategies act to reduce vulnerability by lowering exposure and increasing resilience of elements at risk to climate hazards. Thus, where vulnerability is reduced, the risk associated with impacts of climate hazards is significantly reduced (Lindley et al. 2006).

Appropriate data, knowledge, and information are vitally important to enable the assessment of climate change-related risks and a prerequisite to identifying city-scale adaptation responses. Spatial data and information in particular can provide the knowledge needed to identify context-specific vulnerability, thereby enabling spatially targeted assessments of risk and implementing appropriate adaptation responses across cities. A web-GIS (or Internet GIS) approach enables delivery of GIS data and analysis functions on the Web through the Internet (Peng 2001). Web-GIS tools therefore enable spatial information to be integrated and readily accessible to a wide range of stakeholders, creating a participatory environment and facilitating collaboration in climate change adaptation planning.

This chapter focuses on the development and application of two web-GIS tools to aid climate change adaptation planning, produced as part of the GRaBS Project (see section "The GRaBS Project"). A review of the state of the art in existing online vulnerability, risk, and climate adaptation decision tools was undertaken before the development of the GRaBS Tools began. This review is presented in section "Review of Online Tools for Climate Change Vulnerability, Risk, and Adaptation Assessment." Sections "The GRaBS Climate Change Risk and Vulnerability Assessment Tool" and "The Surface Temperature and Runoff (STAR) Tools" discuss the development and application of the two GRaBS Tools created. Section "Conclusions: Lessons Learned and Key Challenges" concludes the chapter with a discussion of the lessons learned and key challenges for developing and implementing such tools for climate change adaptation planning in cities. 
Table 1 GRaBS project partners

\begin{tabular}{ll}
\hline GRaBS project partner & Location of organization \\
\hline Town and Country Planning Association (TCPA) $^{\mathrm{a}}$ & London, UK \\
\hline The University of Manchester & Manchester, UK \\
\hline London Borough of Sutton $^{\mathrm{b}}$ & Sutton, UK \\
\hline North West Regional Development Agency and Community Forests Northwest & North West Region, UK \\
\hline Southampton City Council & Southampton, UK \\
\hline Provincial Government of Styria & Styria, Austria \\
\hline Municipality of Kalamaria & Kalamaria, Greece \\
\hline KU CORPI & Klaipeda, Lithuania \\
\hline The Amsterdam City District of Nieuw-West & Amsterdam, Netherlands \\
\hline Regional Environment Centre for Eastern Europe & Bratislava, Slovakia \\
\hline Etnambiente SRL & Catania, Sicily, Italy \\
\hline University of Catania & Catania, Sicily, Italy \\
\hline Province of Genoa & Genoa, Italy \\
\hline City of Malmö & Malmö, Sweden \\
\hline
\end{tabular}

${ }^{a}$ Lead partner, with central management, communication, and administrative responsibility

${ }^{\mathrm{b}}$ Responsible for developing the Assessment Tool, STAR Tools, and a database of case studies

\section{The GRaBS Project}

The Green and Blue Space Adaptation for Urban Areas and Eco Towns (GRaBS) project (2008-2011) was a network of 14 leading pan-European organizations involved in integrating climate change adaptation into regional planning and development (Table 1). A key emphasis of the project was upon much needed exchange of knowledge and experience and the actual transfer of good practice on climate change adaptation strategies to local and regional authorities. The ten European municipalities involved represented a broad spectrum of authorities and climate change challenges, all with varying degrees of strategic policy and experience. These authorities were required to develop Adaptation Action Plans (AAPs) - documents to help guide adaptation decisionmaking within their organizations. The AAPs were informed by exchanges of knowledge and experience, together with evidence tools delivered by the research institutions to support policymaking, which included a database of case studies (Kazmierczak and Carter 2010) and online climate change risk and vulnerability assessment tools.

\section{Review of Online Tools for Climate Change Vulnerability, Risk, and Adaptation Assessment}

Prior to designing a web-based GIS tool for urban climate change adaptation assessment, a review was undertaken in 2009 to explore existing vulnerability, risk, and adaptation assessment tools. This review has been updated here to include some more recent examples of tools. A "tool" was interpreted as anything which identified itself as such within the broad climate and adaptation field, found through literature search terms and selected online search engines. Although tools are emerging which attempt to integrate mitigation and adaptation goals, tools focused on mitigation tend not to include strong adaptation elements.

There are widely different views on what constitutes a tool for vulnerability and risk assessment and for risk management in relation to climate adaptation. Certain key criteria used in past reviews were applied here in order to ensure that similar tools were assessed. A review conducted for the United Nations Framework Convention on Climate Change (UNFCCC) refined the definition of an 
adaptation decision tool, specifying that it must have a clear user dimension and the possibility for users to be assisted in the process of evaluating options (Stratus Consulting Inc 1999). In particular it required tools to be able to link adaptation options to impacts and allow an assessment of trade-offs. Tools were also required to have a clear user group, have available documentation, and be applicable at the national, regional, or local scale (Stratus Consulting Inc 1999). While this is a useful definition of an adaptation decision tool, it is also very specific and, subsequently, may be restrictive. For example, applying this definition may exclude some of the useful models or methods subsequently developed, such as the UKCIP Adaptation Wizard (UKCIP 2008). More recent reviews such as Scholze and Wahl (2009) and Garg et al. (2007) apply broader criteria and definitions to adaptation decision tools, allowing inclusion of the most recent developments in adaptation decision tools. For example, Garg et al. (2007) considered tools which tackle both risk and adaptation themes in keeping with the IPCC's definition of vulnerability: "the degree to which a system is susceptible to, or unable to cope with, adverse effects of climate change, including climate variability and extremes. Vulnerability is a function of the character, magnitude, and rate of climate variation to which a system is exposed, its sensitivity, and its adaptive capacity" (IPCC 2007, p. 883).

Garg et al. (2007) analyzed the specific aims and requirements of climate change-related decision support tools for the US Global Change Research Program. The analysis revealed that three core elements were required, as follows:

- Climate change policy development should be supported by providing mechanisms through which methods can be evaluated (such as scenario evaluations, integrated analyses, and alternative analytical approaches). These methods should be demonstrated using case studies.

- Successful climate change adaptive management and planning requires the development of information and other resources. Resources need to be clearly transferred from a research-based environment to an operational environment.

- Assistance is required to help stakeholders prepare appropriate scientific assessments and summaries of information to be used within the decision-making process and as a means to inform other relevant stakeholders as well as the media and the general public. In this context, the IPCC (2007) Fourth Assessment Report indicates that assessments need to be consistent, comparable, and transparent, allow integration, and represent reality as accurately as possible.

Given the huge variation in types of tools which could now be considered a form of climate change vulnerability and risk assessment tool, this review attempts a broad categorization of tools and provides indicative examples of each. Tools can be grouped into five key types. A brief introduction to each of these types is presented below, together with a number of exemplars of each type. It is notable that some tools may cut across one or more of these groups (Garg et al. 2007). Integrated Assessment Models are designed to look at a range of impacts and feedbacks in related sectors. However, no models directly dealing with urban climate risk and adaptation themes were found during the research for this review.

The five key groups of tools are as follows:

1. Risk and adaptation decision-making frameworks (process orientated): These tools are guidelines to completing risk assessments for the purposes of risk management: they do not actually provide the means to conduct risk assessments themselves. These tools guide users through the decisionmaking framework by using the questions that decision-makers would want to have answered as prompts and provide links to other sources to assist with collecting data to answer questions. Examples include the UKCIP Adaptation Wizard and UKCIP Risk Framework, Climate-ADAPT 
Adaptation Support Tool, and the Quality Standards for the Integration of Adaptation to Climate Change into Development Programming (CCA QS, UNDP's structural framework) (Table 2). Although many of these frameworks are generic and valid for all climate-related risks, some are specific to a single-risk theme and provide guidance and examples pertinent to that theme only.

2. Portals or "platforms": These provide a gateway to direct users to a set of more specific tools where information and/or guidance for risk and adaptation decision-making can be obtained. Some include the functionality to support limited manipulation or visualization of data from other sources. In general, they do not enable the creation of new data in response to specific user inputs. Examples include the World Bank Climate Change Data Portal and weADAPT (Table 2). The World Bank Portal includes additional tools for visualizing climate data, specifically the Climate Mapper (also a tool in its own right due to not being fully integrated within the host website). Other portals are much more independent from the tools to which they link, as is the case with the Adaptation Learning Mechanism (ALM) as the tools here are provided as links in a separate resource area.

3. General vulnerability, risk, or impact assessment techniques and approaches which can be applied to climate change risk and adaptation assessment: These are more generic methods, including cost-benefit analysis, expert judgment, and scenario analysis (Willows and Connell 2003; Stratus Consulting Inc 1999). Additional tools useful to spatial planners include identifying constraint (or sieve mapping), tipping points/threshold analysis, high-level risk assessments, and decision pathway tools (ESPACE 2008). For vulnerability assessment a range of indicators, methods, and datasets have been produced, for example, the Social Vulnerability Index for the USA (SoVI). Individual computer-based tools usually incorporate one or more of these approaches, e.g., cost-benefit in addition to other assessment elements.

4. High-level or screening models where new data are created based on input datasets from one or more offline models: These would usually provide functionality to allow data to be manipulated and analyzed to provide new information which may be in real time. Examples include the Climate Wizard (Table 2). Given the challenges for hosting very complex tools on the Internet, online tools are usually of this form rather than very detailed models. These high-level models tend to be at national or regional level, with data at relatively coarse scale. Examples include the MIST tool (Table 2). There are few screening tools available below city scale.

5. Detailed models (usually for individual risk themes or sectors) which require considerable data and resource input and often a high level of technical competence: Such sophisticated models take a long time to run and are therefore less suited to online deployment, though they may run on intranet sites. An example is the Met Office PRECIS tool, a scaled-down climate model which takes days or months to process simulations. These tools have an important role to play, since once processing has completed offline, data outputs can be integrated into high-level models or portals. The AUSSSM and ENVI-met are detailed models for understanding urban heat island mitigation options.

\section{Recommendations for a New Climate Adaptation Decision-Making Tool}

Scholze and Wahl (2009) analyzed the Strengths, Weaknesses, Opportunities, and Threats (SWOT) of existing adaptation decision-making tools (Table 3 ), which are particularly valuable to reflect upon before developing a new tool, both to establish technical and functional requirements and to assist with developing the general "look and feel" of the tool. The opportunities highlighted in Table 3, including awareness raising, stakeholder interest to use and apply, customization to local settings, and developing a toolbox of all tools, are useful ideas to progress. Identified threats to be 


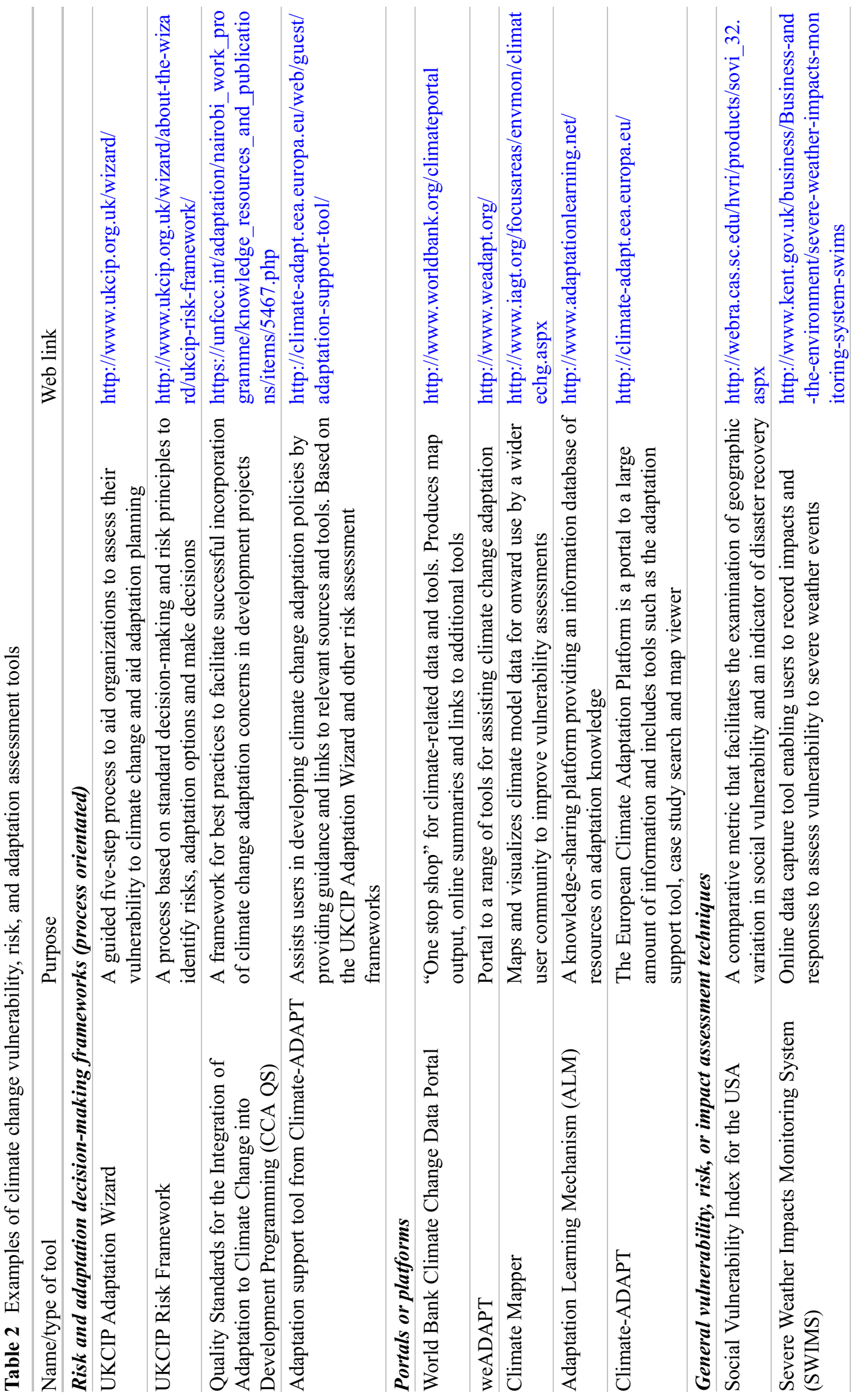




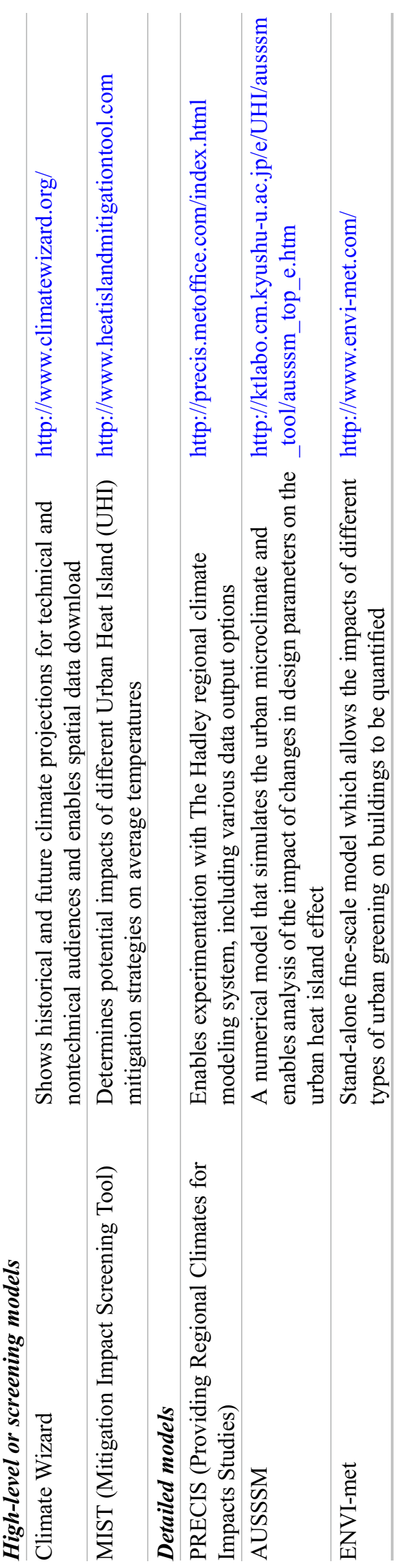


Table 3 Strengths, Weaknesses, Opportunities, and Threats (SWOT) analysis of adaptation decision-making tools (after Scholze and Wahl 2009)

\begin{tabular}{|c|c|}
\hline Strengths & Weaknesses \\
\hline Capacity-building elements & Lack of tools designed for the national level \\
\hline Improved access to climate change information & Lack of consideration of cross-sectoral interactions \\
\hline $\begin{array}{l}\text { Evidence of entrepreneurial spirit in the tool developer } \\
\text { community }\end{array}$ & $\begin{array}{l}\text { Lack of consideration of financial implications (e.g., } \\
\text { cost-benefit analysis) }\end{array}$ \\
\hline \multicolumn{2}{|c|}{$\begin{array}{l}\text { Good handling of physical aspects very well (but are not as good Lack of linkage to disaster risk management } \\
\text { on socioeconomic factors) }\end{array}$} \\
\hline Provision of data for nonexperts in an easy to understand format & Lack of communication of limits and constraints \\
\hline Free, simple to use and open-source tools & $\begin{array}{l}\text { Tools are not always developed with partners and can } \\
\text { be donor-centric }\end{array}$ \\
\hline Assistance with open and transparent decision-making process & Lack of monitoring and evaluation \\
\hline Assistance with decision-making process & Tools do not handle implementation issues \\
\hline \multirow{2}{*}{$\begin{array}{l}\text { Richness in the diversity of tools serving different needs; all are } \\
\text { useful in some way }\end{array}$} & Online tools depend on good Internet connectivity \\
\hline & Need more engagement with soft solutions \\
\hline Opportunities & Threats \\
\hline Customization to local settings & $\begin{array}{l}\text { Resources could be wasted if there is too much overlap } \\
\text { and poor coordination }\end{array}$ \\
\hline Stakeholder interest to use and apply tools & Oversimplistic tools \\
\hline Creation of a toolbox of all tools & $\begin{array}{l}\text { Overshadowing of existing tools and policies and } \\
\text { creation of "climate bias" }\end{array}$ \\
\hline $\begin{array}{l}\text { Cataloging all tools to see whether new tools are necessary to } \mathrm{Cc} \\
\text { fill gaps }\end{array}$ & Competing tools \\
\hline \multicolumn{2}{|l|}{ Greater coordination/collaboration needed } \\
\hline \multicolumn{2}{|l|}{$\begin{array}{l}\text { Creation of high-quality tools through links to research and the } \\
\text { scientific community }\end{array}$} \\
\hline \multicolumn{2}{|l|}{ Awareness raising (public and data needs) } \\
\hline \multicolumn{2}{|l|}{ Business opportunities } \\
\hline \multicolumn{2}{|l|}{ Development of peer review mechanisms } \\
\hline \multicolumn{2}{|l|}{ Including adaptation and mitigation } \\
\hline \multicolumn{2}{|l|}{ Capturing of local knowledge } \\
\hline \multicolumn{2}{|l|}{ Handling trade-offs } \\
\hline \multicolumn{2}{|l|}{$\begin{array}{l}\text { Identification of tools useful in particular settings and for } \\
\text { particular tasks }\end{array}$} \\
\hline \multicolumn{2}{|l|}{$\begin{array}{l}\text { Integration of disaster risk management ideas to ensure } \\
\text { valuable knowledge not missed }\end{array}$} \\
\hline Data quantity/quality transparency and assessment & \\
\hline
\end{tabular}

avoided include the challenge of making tools sufficiently reliable yet easy to use for a wide audience. Further, while online tools enhance access to evidence to support climate change adaptation and decision-making, a key weakness identified is the dependence on good Internet connectivity. Internet connection speeds and coverage have greatly improved in the last 20 years. However, detailed climate change information may by necessity be data intensive, and therefore models over the Internet may be prone to slow down.

Drawing upon this SWOT analysis, recommendations for new tools include to place the tool within a clear risk management and adaptation assessment framework/process, to house the tool within a website which acts as a data/tool portal, to ensure that terminology is clear and full 
documentation is provided for users, to ensure that the functions include those provided in existing tools, and to consider the possibility of a data upload element in the tool.

This review identified that there was no existing tool specifically for vulnerability assessment and that there was scarcity of tools specifically focused on cities and associated themes of interest. Furthermore, the use of a web-GIS approach is an accepted format for the development of tools in climate change adaptation planning. A web-GIS (or Internet GIS) approach enables delivery of GIS data and analysis functions on the Web through the Internet (Peng 2001). Spatial representations are important in the planning process, and web-GIS can enhance the traditional planning process through its interactive map exploration features (Dragicevic and Balram 2004). Dragicevic (2004) identifies three main ways that web-based GIS has enhanced the open use of GIS: spatial data access and dissemination; spatial data exploration and geovisualization; and, spatial data processing, analysis, and modeling. Web-GIS can effectively support the task of integrating data from disparate sources, making these available through the whole planning process, thereby enabling open and transparent decision-making (Dragicevic and Balram 2004).

\section{The GRaBS Climate Change Risk and Vulnerability Assessment Tool}

The GRaBS Climate Change Risk and Vulnerability Assessment Tool (hereafter, Assessment Tool) follows the principles of an online Public Participation GIS (Kingston et al 2000; Kingston 2007). The main aim was to develop web-based Geographical Information Systems (GIS) to enhance public involvement and participation in environmental planning and decision-making. These systems are referred to as PPGIS and are a form of Planning Support System. The main objective is based on the belief that by providing all stakeholders, including citizens, with access to information and data in the form of maps and visualizations, they can make better informed decisions about the natural and built environment around them.

\section{Development of the GRaBS Assessment Tool}

Development of the Assessment Tool followed an explicit methodology (Fig. 1). Following the review of existing state-of-the-art risk and adaptation tools, the project team embarked on a collaborative process of tool development with all the GRaBS partners (Table 1), in order to shape the exact form and function of the final Assessment Tool (Fig. 1). This process involved using Checkland's (1999) soft systems methodology to inform system development. Firstly, a user

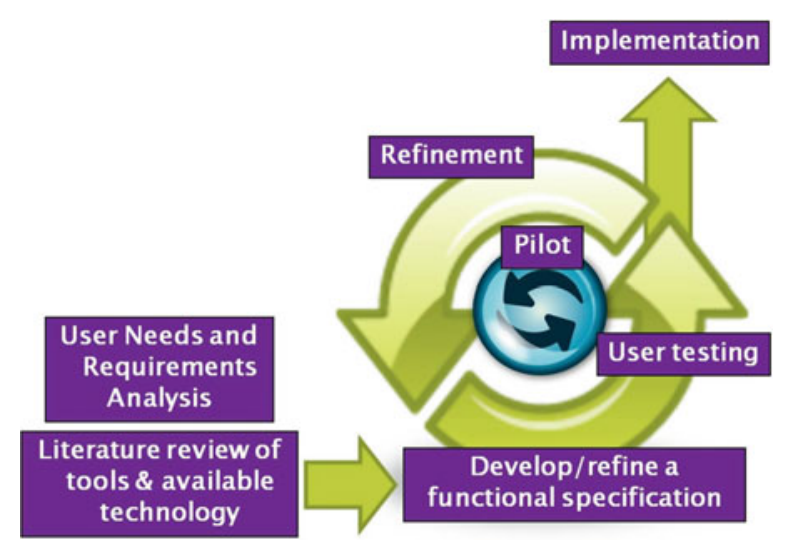

Fig. 1 The GRaBS Risk and Vulnerability Assessment Tool development process (Cavan and Kingston 2012) 
needs and requirements analysis of all partners was carried out via an online questionnaire to inform the writing of the functional specification which fed into the building of the beta version of the tools. This was piloted at a user workshop to test functionality and usability. Feedback from this workshop then led to numerous refinements to the tool followed by further user testing and refinement before the tools were fully deployed. This process is reported in detail in Cavan and Kingston (2012).

The nature of the GRaBS project with a pan-European user-base meant that the tool had to be built using a common map base for all partners. Using Google Maps' Application Programming Interface (API) which is free, generic, highly customizable, and probably, most importantly from a user perspective, very simple to use and navigate, meant that a single generic tool could be built for all partners. The GIS data is served over the top of Google Maps using MapServer, which converts proprietary spatial GIS data into an image format (in this case png) which speeds up the map rendering process for the user. This also means that the user of the Assessment Tool does not have access to the source GIS data, overcoming data access restrictions which might apply to some of the datasets depending upon their source of origin. The tool can therefore be categorized as a high-level or screening tool because the data used in the model is processed offline and the tool does not involve real-time processing of models (Scholze and Wahl 2009).

The Assessment Tool adopts a spatial screening risk assessment framework (Lindley et al. 2006, 2007), whereby an explicit set of spatial data layers are created in order to represent each component of risk (including separate layers representing hazard, vulnerability, and exposure). GIS overlay is used to represent the spatial coincidence that would be required in order for risk to be realized at a particular location. Thus, the online Assessment Tool presents climate change risks and vulnerabilities at a range of spatial scales from EU-wide to the neighborhood. The Assessment Tool allows decision-makers to overlay different raster, point, and polygon data layers to visually assess their spatial relationships and examine appropriate attribute information (Fig. 2b). For example, the user can investigate the spatial incidence of flood hazard, together with the distribution of vulnerable people, social and critical infrastructure.

There are over 350 different spatial layers in the Assessment Tool, with 32 EU-wide layers, and individual partner level data ranging from 7 to over 60 layers. This includes geospatial data from the following categories:

- Green and blue space, e.g., parks, public open space, rivers, canals, and lakes

- Vulnerability indicator, e.g., people aged over 75 years, people living on a low income

- Social infrastructure, e.g., schools, hospitals, fire stations, and public buildings

- Civil infrastructure, e.g., power stations, water treatment works, and railway stations

- Hazard, e.g. river, surface water, and sewer flood risk areas

- Vulnerability index, e.g., people vulnerable to flooding and high temperatures

- Population structure, e.g., population density and deprivation

- Urban development, e.g., building types and residential areas

The variability in the amount of local level data reflects both the extent to which different municipalities have been collecting relevant geospatial data and their ability to work across departmental boundaries to obtain necessary information. Additionally, qualitative information provided in hundreds of data notes offers important background information on the issues of climate change, vulnerability, and adaptation, including an explanation of key terms and why each layer may be important to consider in climate change adaptation planning. A summary of the key elements and functions of the Assessment Tool is provided in Fig. 3. 


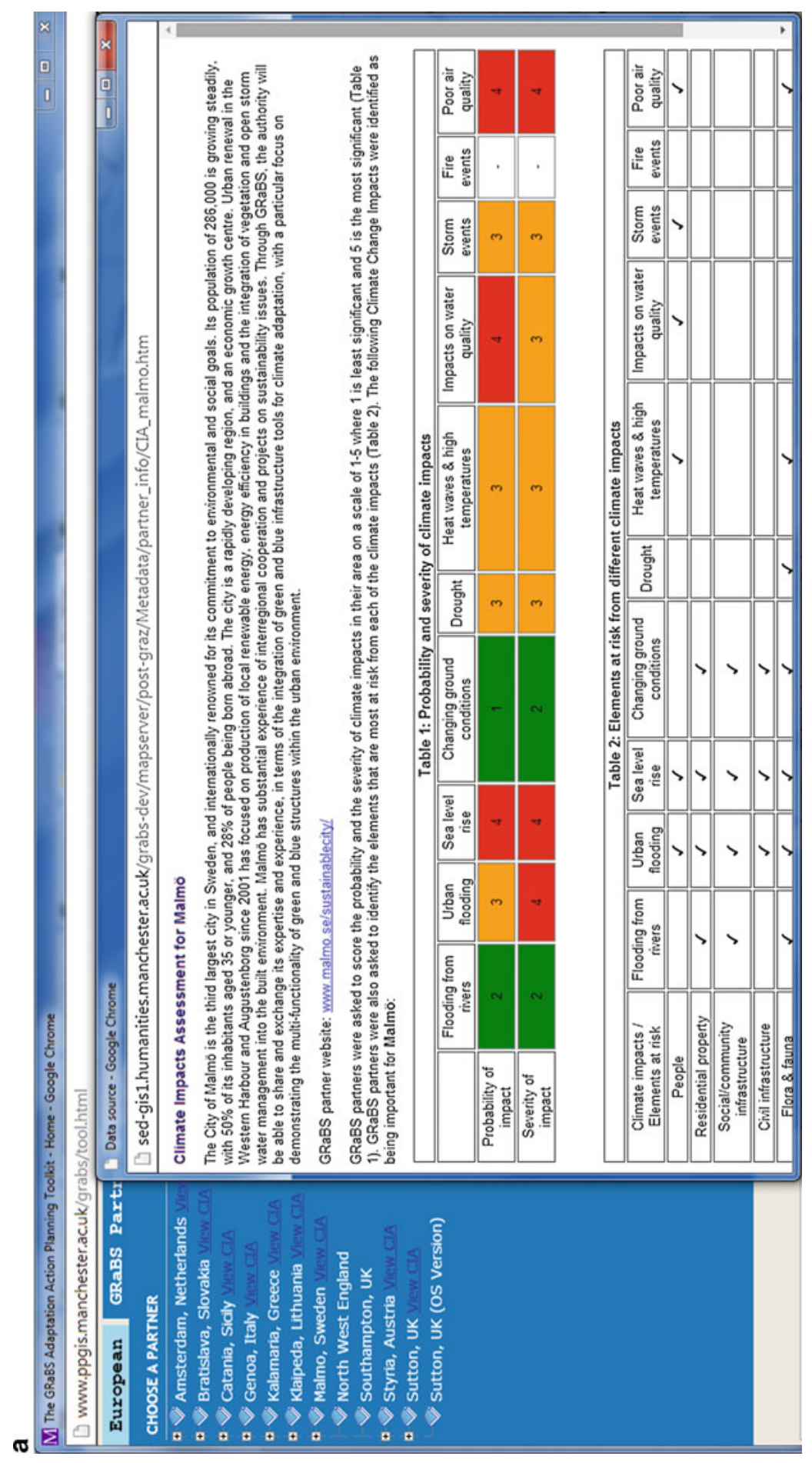




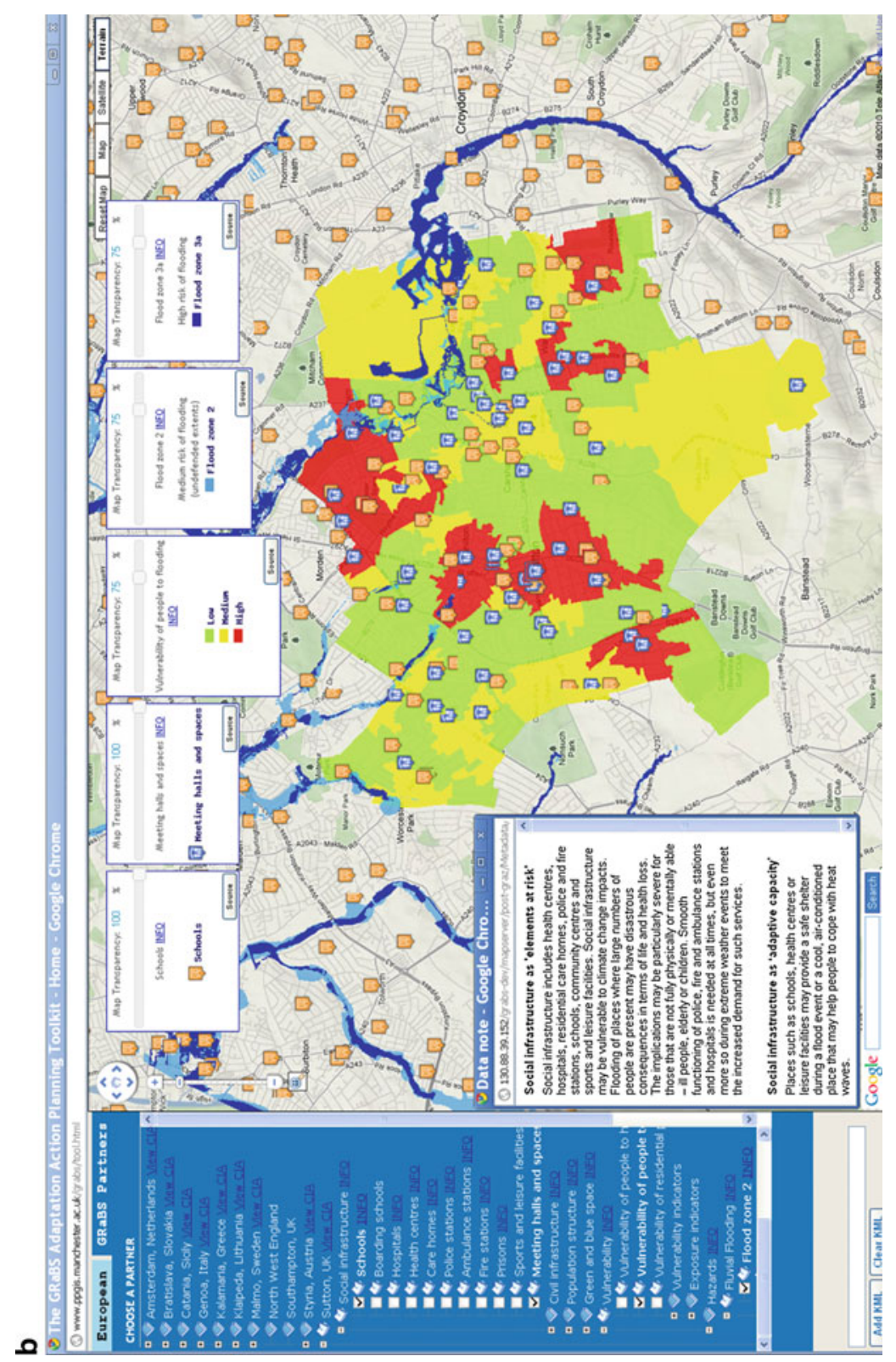

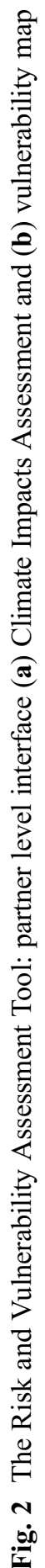




\begin{tabular}{l|l|}
\hline ELEMENTS & EXPLANATION \\
\hline Portal & $\begin{array}{l}\text { The tool is housed in a website which acts as a portal and provides other } \\
\text { tools and guidance for risk and adaptation decision-making }\end{array}$ \\
\hline $\begin{array}{l}\text { Risk management } \\
\text { framework }\end{array}$ & $\begin{array}{l}\text { The tool is structured around a risk framework, including the themes of } \\
\text { vulnerability, hazard, exposure, risk and elements at risk } \\
\text { The tool has two levels of operation - European and case study level, } \\
\text { which includes the GRaBS project partners' study areas } \\
\text { levels }\end{array}$ \\
\hline $\begin{array}{l}\text { Climate impact } \\
\text { assessment (case } \\
\text { study level only) }\end{array}$ & $\begin{array}{l}\text { A pop-out window provides an assessment of the climate hazards and } \\
\text { elements at risk of key importance within the GRaBS partners' area }\end{array}$ \\
\hline FUNCTIONS & $\begin{array}{l}\text { Real-time display of point, polygon and raster geospatial data layers } \\
\text { Overlay of up to five geospatial data layers }\end{array}$ \\
\hline Visualisation & \begin{tabular}{l} 
A slider bar enables the user to adjust the transparency of the colour of a \\
theme to enable the base map to be viewed more easily or to enhance the \\
overlay function \\
\hline Overlay
\end{tabular} \\
\hline Transparency & $\begin{array}{l}\text { Map navigation functions } \\
\text { Pop-up window providing clear terminology and interpretation of the data }\end{array}$ \\
\hline Zoom, pan & $\begin{array}{l}\text { Pop-up window providing metadata information } \\
\text { Enables querying of the attribute information of the geospatial data }\end{array}$ \\
\hline Data note & $\begin{array}{l}\text { Enables upload of local data - particularly useful for sensitive or restricted } \\
\text { information }\end{array}$ \\
\hline Data source & The user can view satellite, terrain or map modes \\
\hline Add kml &
\end{tabular}

Fig. 3 Key elements and functions of the Risk and Vulnerability Assessment Tool (Cavan and Kingston 2012)

User guidance included the creation of three storylines or use cases (Cockburn 2000), which offer typical examples of how an individual or organization might use the Assessment Tool to support climate change adaptation policy and decision-making within their organization.

\section{Application of the Risk and Vulnerability Assessment Tool Across Europe}

Adaptation Action Plans (AAPs) were the key output of the GRaBS project from 11 of the partners - the municipal or regional planning authorities and partners that provide a planning support function. The AAPs were developed via a six-stage cyclical process, as follows:

1. Baseline review and process launch

2. Raise awareness and explore adaptation responses

3. Agree high-level aim and objectives

4. Agree delivery program

5. Implementation and monitoring

6. Evaluation and reporting

The AAPs represent a potentially significant influence over adaptation issues in the areas that they cover and support the partner urban areas and regions in developing responses to climate change and extreme weather. The key role of the Assessment Tool in supporting the GRaBS AAPs was identified through better understanding the connections between the Assessment Tool and three interlinked issues - the objectives of AAP development, the stages of AAP development, and the generic barriers constraining effective adaptation (Carter et al. 2010; Fig. 4). Taking these issues collectively, the Assessment Tool was identified as able to support adaptation planning and decisionmaking in four key areas: (1) raising awareness of climate change impacts and adaptation responses, (2) encouraging participation in adaptation planning, (3) enhancing data availability and use, and (4) supporting decision-making. 


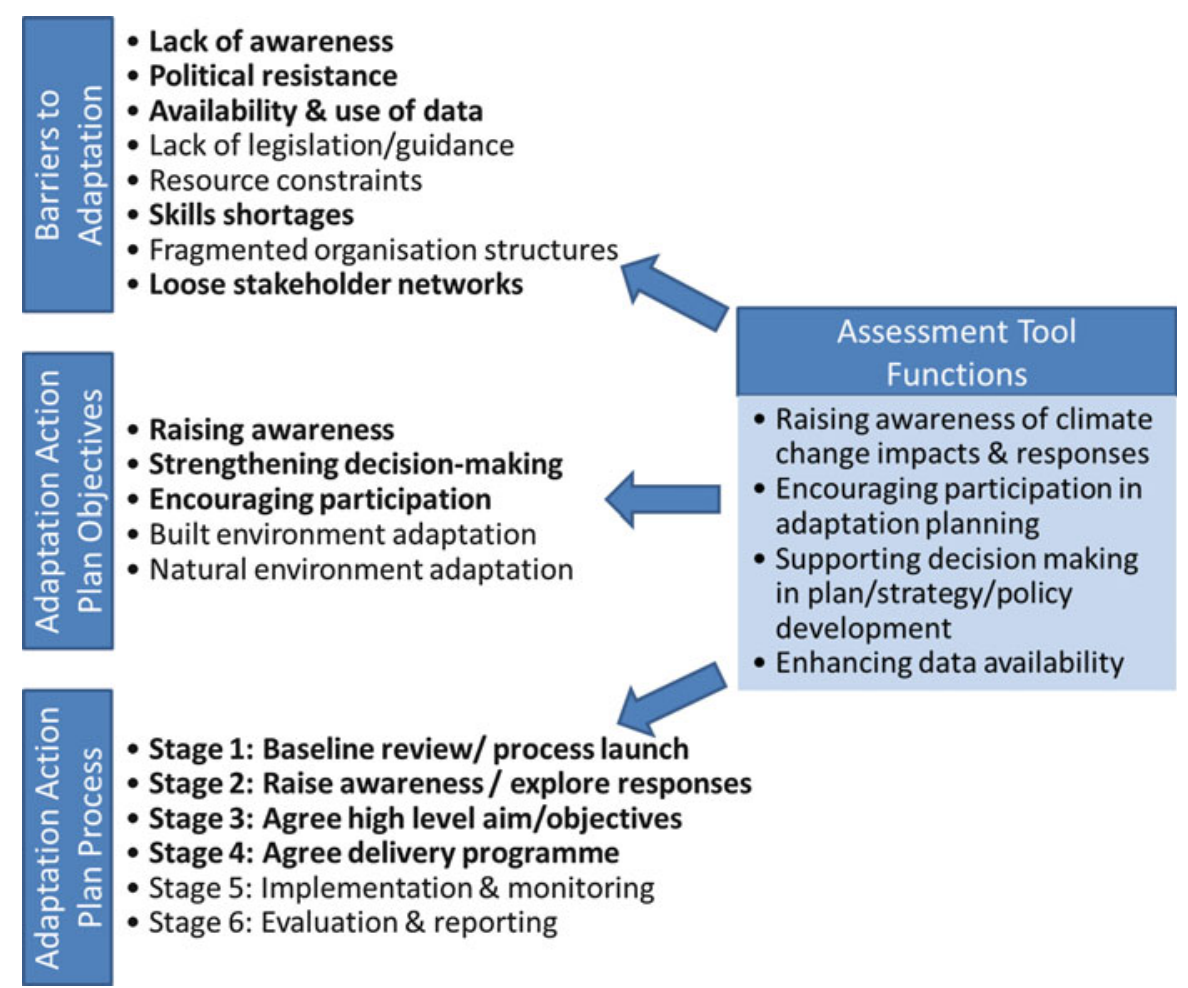

Fig. 4 The role of the Risk and Vulnerability Assessment Tool in supporting the GRaBS Adaptation Action Plans (After Carter et al. 2010)

A questionnaire sent to GRaBS partners (Table 1) in January 2011 allowed an evaluation of how the Assessment Tool had been applied, the identification of lessons learned, and suggestions for future development. The following sections present an analysis of this information in the context of the key areas identified above.

\section{Raising Awareness of Climate Change Impacts and Adaptation Responses}

Raising awareness of climate change is an important early stage in the process of developing adaptation responses and can help to improve the adaptive capacity of individuals and stakeholders who have an important role in responding to associated impacts (Carter et al. 2010).

The Assessment Tool was an excellent means of raising awareness of climate hazards and vulnerability among the public and decision-makers and a way to visualize "what can happen and what we need to take action on" (Cavan and Kingston 2012, p. 265). The Assessment Tool was demonstrated at many awareness raising events held for both internal and external stakeholders focused upon climate change impacts and local adaptation responses. A common structure to these events involved providing an introduction to climate change adaptation issues, the GRaBS project and Assessment Tool, a live demonstration of the Assessment Tool, and/or hands-on workshop session, questions, and discussion. The feedback from workshops was positive, with an emphasis on its user-friendly interface and useful spatial and contextual information provided in data notes.

It was noted that specific discussion at awareness-raising events depended upon the audience. When the Assessment Tool was presented to the public or private sector stakeholders with greater adaptation expertise, discussions often stimulated more questions than answers, for example: 
- Regarding the capability (or limitations) of the Assessment Tool

- How to plan for future scenarios

- Its transferability to local authorities beyond the GRaBS partnership and the accessibility of relevant data

- Its principle use for awareness raising among local councilors or communities

- Conflicts with existing GIS tools in terms of building an evidence base for planning

\section{Encouraging Participation in Adaptation Planning}

Developing adaptation responses in urban areas is complex due to the ubiquitous nature of climate change impacts occurring across different sectors and spatial scales. Bringing stakeholders together in stakeholder workshops and community events can facilitate establishment of collaborative networks and generate consensus and a shared vision toward adaptation issues and responses, which will enhance the effectiveness of the AAP implementation process.

The Assessment Tool was valuable in encouraging participation in adaptation planning at stakeholder workshops and community events. For example, the London Borough of Sutton held a stakeholder workshop which incorporated a practical computer session for around 35 participants, including representatives of statutory bodies such as the Environment Agency, Natural England, and utilities (e.g., Thames Water), in addition to officers from a range of local authority departments. After an introduction to the GRaBS project, a hands-on workshop session enabled participants to explore the Assessment Tool. The discussion and feedback sessions were particularly valuable for the development of Sutton's "Community Map" (see section "Enhancing Data Availability and Use").

The Northwest England partner (NWDA and Community Forest Northwest) connected the Assessment Tool to other resources and tools aimed at encouraging participation in adaptation planning. The Community Forest Northwest website "Green Infrastructure to Combat Climate Change" includes a wealth of resources developed through the GRaBS project including action guidance, an evidence base, an evidence report, and a link to the Assessment Tool. Specifically, the Community Forest Northwest encouraged stakeholders and community groups to apply the Assessment Tool through two key mechanisms:

- The "Framework for Action" - an action guidance document that can be used to aid issues concerning policy development and delivery.

- "Community Adaptation Training" - whereby the Assessment Tool is provided as one activity for community groups in the training materials. The training is intended for use by professionals with community groups to engage them on the need for climate change adaptation and/or how their local green infrastructure helps to adapt their neighborhood to climate change.

\section{Enhancing Data Availability and Use}

Data availability was highlighted as a key barrier to climate change adaptation planning. The process of developing the Assessment Tool raised significant issues regarding data accessibility and availability within planning authorities, which need addressing if adaptation action is to be delivered successfully. A key function of the Assessment Tool is that it required the collation of spatial data in a consistent format to support adaptation planning. For the Municipality of Kalamaria, a lack of access to relevant data in relation to climate change vulnerability was a pertinent issue, and the AT's role also included identification of the gaps in necessary data:

\footnotetext{
${ }^{1}$ Green Infrastructure to Combat Climate Change: http://www.greeninfrastructurenw.co.uk/climatechange/
} 
Awareness raising may be the most important use. The general lack of data on our behalf grabbed the attention of the attendees. . Vulnerabilities have not been recorded for the climate change impacts at a local level in Greece so there is a need for them for proper estimation of risk.

Using a consistent framework throughout the Assessment Tool added significant value and allowed partners to investigate each other's local datasets, to assist in the development of their own tool. For example, the Amsterdam City District of Nieuw-West revealed that:

We used other partner tools to demonstrate that there are still crucial data layers missing in our tool. By showing the value of these layers we hope that in the future, we can still gather these data and add them to the tool.

The Assessment Tool development process required the collation of data across different departments, thereby facilitating cross-departmental working and awareness raising among local authority staff. A key finding of the project was the need to break down silos between departments in order to gather evidence on the need to act on adaptation and to support adaptation planning.

The development of the Assessment Tool also stimulated GRaBS partners to develop local online GIS tools and portals. This includes the Province of Genoa's ADAPTO Adaptation Action Planning Toolkit, which enables visualization of local indicators for the assessment of the vulnerability of environmental parameters (Provincia di Genova 2013). In addition, the London Borough of Sutton developed their own web-GIS to facilitate community engagement and feedback on climate change and flooding issues at the neighborhood scale. The London Borough of Sutton (2013) online "Community Map" incorporates a comprehensive range of environmental issues relating to the delivery of council services, in addition to adopting the conceptual risk framework and relevant geospatial information from the Assessment Tool.

\section{Supporting Decision-Making}

The Assessment Tool supported decision-making in three ways: within Adaptation Action Plans, internal strategies, and through guidance documentation. The role of the Assessment Tool in the GRaBS AAP process differed between partners according to the form and function of the AAP, the stage of the AAP process that the Assessment Tool was applied, and the local information available to each partner (Carter et al. 2010). Thus, the application of the Assessment Tool within AAPs also differed between partners, which ranged from explicit inclusion in high-level policy statements and delivery programs to use for gathering material to inform the development of the AAP, e.g., through analysis of the spatial data, to stakeholder workshops and meetings. Within the time frame of the GRaBS project, the Assessment Tool was applied at the first two stages of the AAP process by all of the GRaBS partners responsible for producing AAPs, where stage 1 is a baseline review and process launch and stage 2 is raise awareness and explore adaptation responses (Fig. 4).

Additionally, the Province of Genoa, Southampton City Council, and London Borough of Sutton incorporated the Assessment Tool into stages 4 and 5 (agree high-level aim and objectives and agree delivery program; Fig. 4). For example, Action 4 of the Province of Genoa's high-level policy statement states that

Vulnerability to climate change risks, and adaption measures should be evaluated through a reliable, updated and flexible tool, able to answer specific local issues; then, the GRaBS assessment tool should be used both for building programmes and Provincial level, both for delivering green and blue infrastructure projects in homogenous physical contexts. (Provincia di Genova 2011)

Priority 4 of Southampton City Council's AAP "we will minimise the impact from flooding for the city" stated that it should implement the Assessment Tool in the Council's delivery program (Fig. 5). Additionally, Southampton City Council applied the Assessment Tool in internal strategies, specifically, strategic decision-making for climate change adaptation planning: 


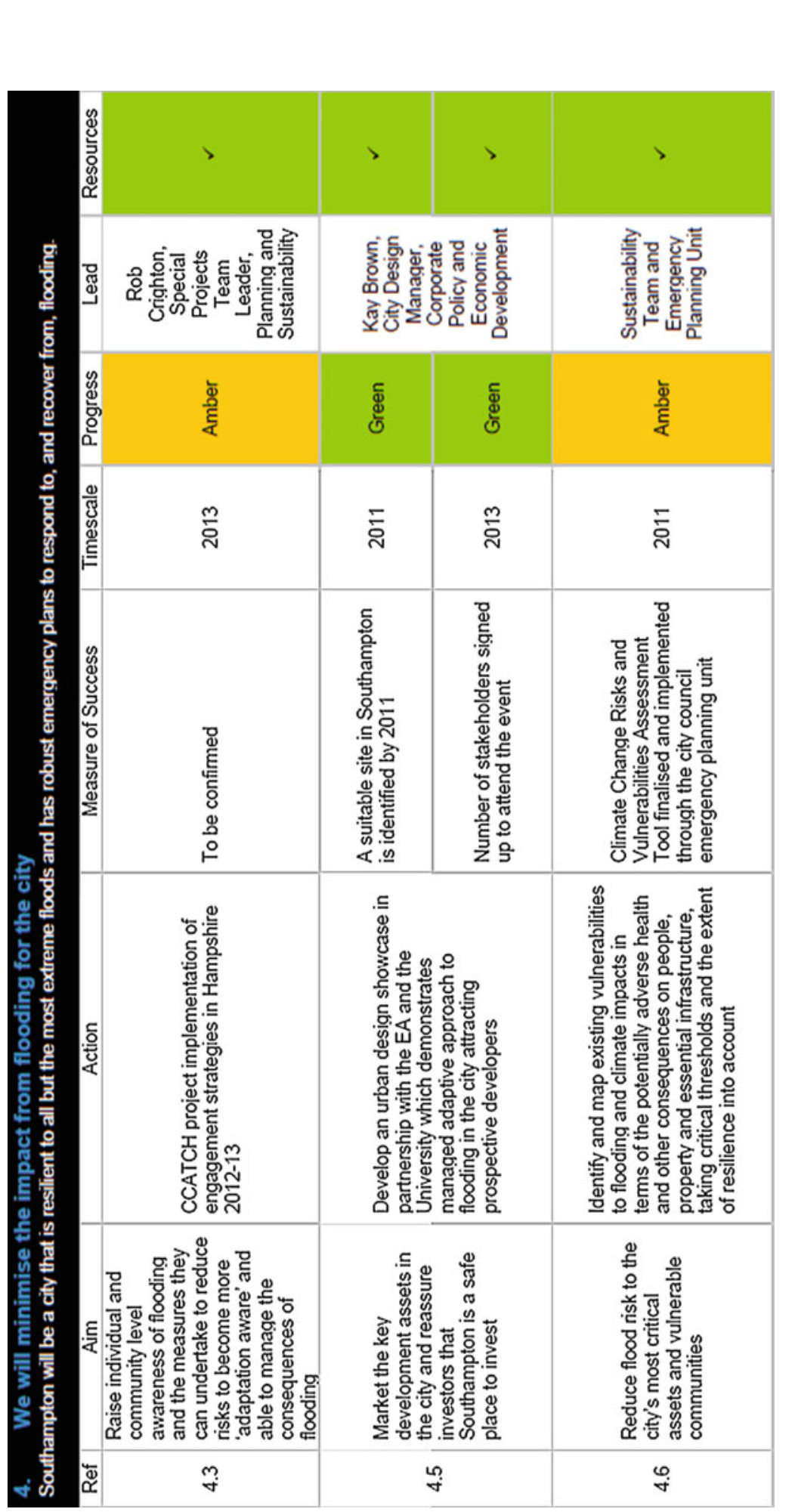

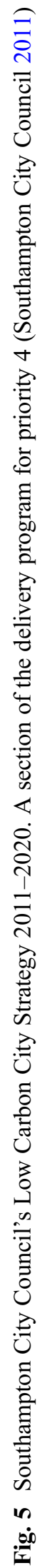


It has been used internally by officers, already familiar with climate related risks, to help inform strategy work that is currently underway. In particular, it has been used to test the validity of assumptions about areas of the city that were believed to experience problems.

\section{Suggestions for Future Tool Development}

The final part of the questionnaire aimed to gather comments about future tool development, specifically, if there was a future version of the tool, what would users want it to do? Many of the GRaBS partners expressed the desire for the Assessment Tool to include future modeling scenarios, e.g., for land use, development, and climate, over various time horizons, including the "possibility to show a "before and after" situation about climate change adaptation effects in the region," and "the tool should also include the information on vulnerable objects (not only existing ones, but also planned developments)." The flexible spatial screening risk assessment framework adopted does allow assessing scenarios of different adaptation options, by adding new layers representing each component of risk according to potential future changes. However, such scenario development requires significant scientific research to be conducted at case study level before such spatial data layers can be included. The Assessment Tool therefore can at present only deal with current vulnerability to climate change. The Surface Temperature and Runoff (STAR) Tools were later developed to address this limitation and provide some modeling capabilities, which is the focus of the next section.

\section{The Surface Temperature and Runoff (STAR) Tools}

There is an increasing body of literature that emphasizes the multifunctional benefits of green infrastructure and its important role in adapting urban areas to climate change through, for example, flood alleviation and temperature regulation (Gill et al. 2007; Bowler et al. 2010). However, it is important to be able to quantify such benefits in order to illustrate the importance of green infrastructure and to highlight how changes to the built environment at a local level can affect the delivery of important ecosystem services it provides.

The STAR Tools is an online toolkit that enables users to assess the potential of green infrastructure in adapting urban areas to climate change (Fig. 6a). It includes two modeling tools - a Surface Temperature (ST) and a Surface Runoff (SR) Tool - both of which are underpinned by scientific models (see Gill 2006 for full details):

- Surface Temperature Tool: developed from an urban climate model (Tso et al. 1990, 1991; Whitford et al. 2001) and produces outputs of maximum surface temperature expected during the two hottest days in summer for a specified study area (98th percentile). Since the mix of different land surfaces (such as proportion of green cover, water, and buildings) is an important determinant of the land surface temperature, these parameters are also accounted for in the model.

- Surface Runoff Tool: based upon the US Soil Conservation Service approach (SCS 1972), this tool outputs the percentage of the rainfall that becomes surface runoff and the volume of the surface runoff for a given amount of daily rainfall. The Surface Runoff Tool thus calculates how much rainfall from a given event will not be converted to surface runoff; this could be because this rainfall is intercepted (e.g., by plants and vegetation), infiltrated (e.g., into the soil), or stored (e.g., on surfaces). The remaining rainfall is converted to surface runoff. Again, the land surface cover type is an important determinant of rainfall runoff and is accounted for in the model, as is soil type. 

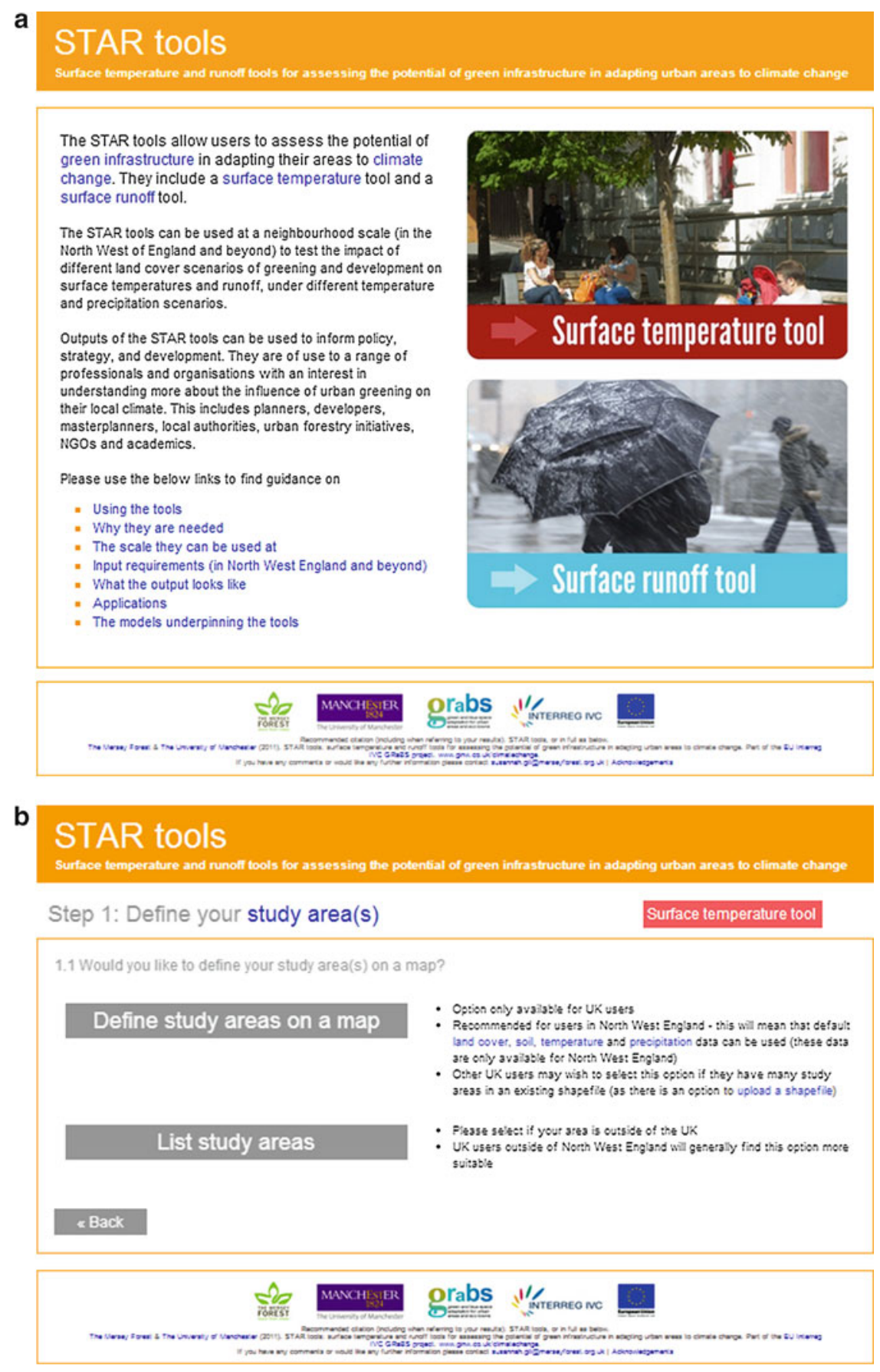

Fig. 6 The STAR Tools interface, (a) homepage, (b) defining a case study area, http://maps.merseyforest.org.uk/grabs/

The STAR Tools are applicable for the "neighborhood" scale (recommended between 0.4 ha and $4 \mathrm{~km}^{2}$ ), though they can be run for more than one neighborhood or study area at a time. The STAR Tools have few input requirements and are straightforward to use. The key benefit of the STAR Tools is that they allow the role of urban vegetation to be explored. This is possible through creating "what if" scenarios for both climate and land surface cover, for example, running the STAR Tools with the 
"business as usual" or current climate and land surface cover, compared to adding $10 \%$ green cover and comparing the resulting output surface temperature or runoff. If several neighborhoods are run, the results can be mapped using GIS (see sect. - Application of the STAR Tools to inform the Mersey Forest Plan), although this functionality is not available in the tool itself.

The STAR Tools enable assessment of how surface temperatures and runoff may vary under future climate projections and as the proportion of green space is increased or decreased. Thus, it can help to answer important questions such as: given the changing climate, how much greening do we need in particular areas to achieve certain reductions in temperatures or runoff in the future? What impact would a proposed development have upon temperature or runoff at the neighborhood scale? Such information could also be used to set targets for green infrastructure provision within new developments or in existing neighborhoods. In this way, the information could be used to guide policy and strategy development - both urban development and green infrastructure policies. The outputs of the STAR Tools are thus potentially of use to a range of professionals including planners, developers, master planners, local authority officers, NGOs, urban forestry initiatives, and academics.

\section{Developing the STAR Tools}

The STAR Tools were developed as an addition to the Assessment Tool, in response to feedback regarding the desire to project future land use scenarios and their potential impact. While the development of the STAR Tools was focused upon North West England (one of the GRaBS case study locations), it was important that users outside of this area could also apply the STAR Tools to investigate the potential of green infrastructure in adapting their specific urban neighborhood to climate change. Therefore, users enter the Tools in two ways (Fig. 6b). If the study area is located in the UK, users can define their study area(s) on an interactive map, driven by OpenLayers and Ordnance Survey's OpenSpace. All default input values are automatically provided for the Mersey Belt within North West England, including climate projections, land surface cover, and soil data, together with detailed information about data sources and model assumptions. Users also have the option to simply list their study areas. At the next stage, the user is then able to both insert their own input values (including climate projections, land surface cover, and soils) and modify the default model parameter values (set to North West England climate and environment context) to adapt the STAR Tools to their particular case study area. While this option may be more suited to academic or more technical users, it ensures that the STAR Tools can potentially be used for any location, and full guidance is provided regarding the default parameters and model assumptions.

The technical development of the STAR Tools involved representing the two underpinning models as web-based tools. Server side, the processing is carried out in PHP running on an Apache server with MapServer. Spatial processing is carried out using GDAL/OGR and MapScript. Data is stored in a MySQL database. AJAX techniques are used to communicate between the client- and server-side scripts. Web Map Services and Web Feature Services are used to serve spatial data to the front end.

Since the STAR Tools were launched in early 2012, they have had 1,100 unique visitors, with over 200 progressing to the results page. ${ }^{2}$ Regarding the origin of users, $64 \%$ of visitors are from the UK, $5 \%$ from the USA, and smaller numbers were from Brazil, Spain, Belgium, and other countries. Information captured by the optional online questionnaire reveal that the STAR Tools have been used by policymakers, researchers, and green infrastructure professionals to guide policy and for academic research purposes. 


\section{Application of the STAR Tools to Inform The Mersey Forest Plan}

The Mersey Forest is a community forest in North West England, covering $1,370 \mathrm{~km}^{2}$. Established in 1991, it is a partnership of local authorities, national government agencies, land owners, businesses, and local communities. Its vision is to get "more from trees" to help make Merseyside and North Cheshire one of the best places to live in the country. The partnership has planted over nine million trees and doubled woodland cover since 1991, with three times more trees planted than the England average. This has attracted investment, boosted health and well-being, and improved the local environment.

The Mersey Forest Plan is the long-term and strategic guide to the work of The Mersey Forest team and partners. While it is not a statutory planning document in its own right, under the National Planning Policy Framework "an approved community forest plan may be a material consideration in preparing development plans and in deciding planning applications" (DCLG 2012). The Mersey Forest Plan was first written in 1994, updated in 2001, and has been refreshed again in 2014.

Since the earlier versions of the plan, climate change has risen up the policy agenda. In the early versions there is a brief acknowledgement of the "local and global atmospheric benefits" of trees and woodlands. In addition, reference is made to what we would now recognize as both the mitigation and adaptation benefits of trees and woodlands; specifically, "forestry locks up carbon and offsets other carbon dioxide emissions, helping to reduce global warming. Forests also have more local benefits in filtering out air pollutants, especially dust, reducing noise and acting as windbreaks. The shelter they provide will also improve the local climate of open spaces and has been shown to reduce the cost of heating buildings" (The Mersey Forest 1994, p. 16).

There was a clear need, which was recognized by The Mersey Forest partners, for climate change to have greater prominence in the refreshed plan. As such, it features as one of 20 policies set out under the headings "Who, What, How and Why" and is also cross-referenced in many of the other policies. The specific policy on climate change states, "We will safeguard, plant and manage trees and woodlands for their role in climate change mitigation, adaptation, and resilience - such as providing urban cooling, carbon storage, flood alleviation and water management, helping wildlife adapt, low carbon fuels and products, sustainable travel routes, and outdoor recreation opportunities. We will design, plant and manage them to increase their resilience to potential climate change impacts, such as changing pests and diseases" (The Mersey Forest 2014, p. 52).

The STAR Tools and the Surface Temperature Tool in particular provided evidence to support this policy. The Surface Temperature Tool was run for the 210 wards within The Mersey Forest for the baseline climate (1961-1990) and for the 2050s high emissions scenario (at the $10 \%, 50 \%$, and $90 \%$ probability levels). The default temperature scenarios supplied with the tool (available for North West England) were used. It was also run for the current land cover scenario (again, using the default values supplied) and for two further scenarios where $10 \%$ green cover was either added or removed. When green cover was added, the same percentage was removed firstly from other impervious surfaces and then, if this did not meet the full $10 \%$, sequentially from major roads, buildings, and bare soil or gravel (and vice versa for when green cover was removed). In a few instances, in wards where either green cover was already above $90 \%$ or below $10 \%$, it was not possible to add or remove the full $10 \%$ green cover, and therefore, green cover was only added or removed to the maximum amount possible.

Since the Surface Temperature Tool was run for 210 case study areas (wards), the output was mapped using GIS and features within the plan (Fig. 7). The results found the hottest ward to be

\footnotetext{
${ }^{2}$ Unique visitors are defined as an individual user (or computer). Statistics were taken in December 2013.
} 

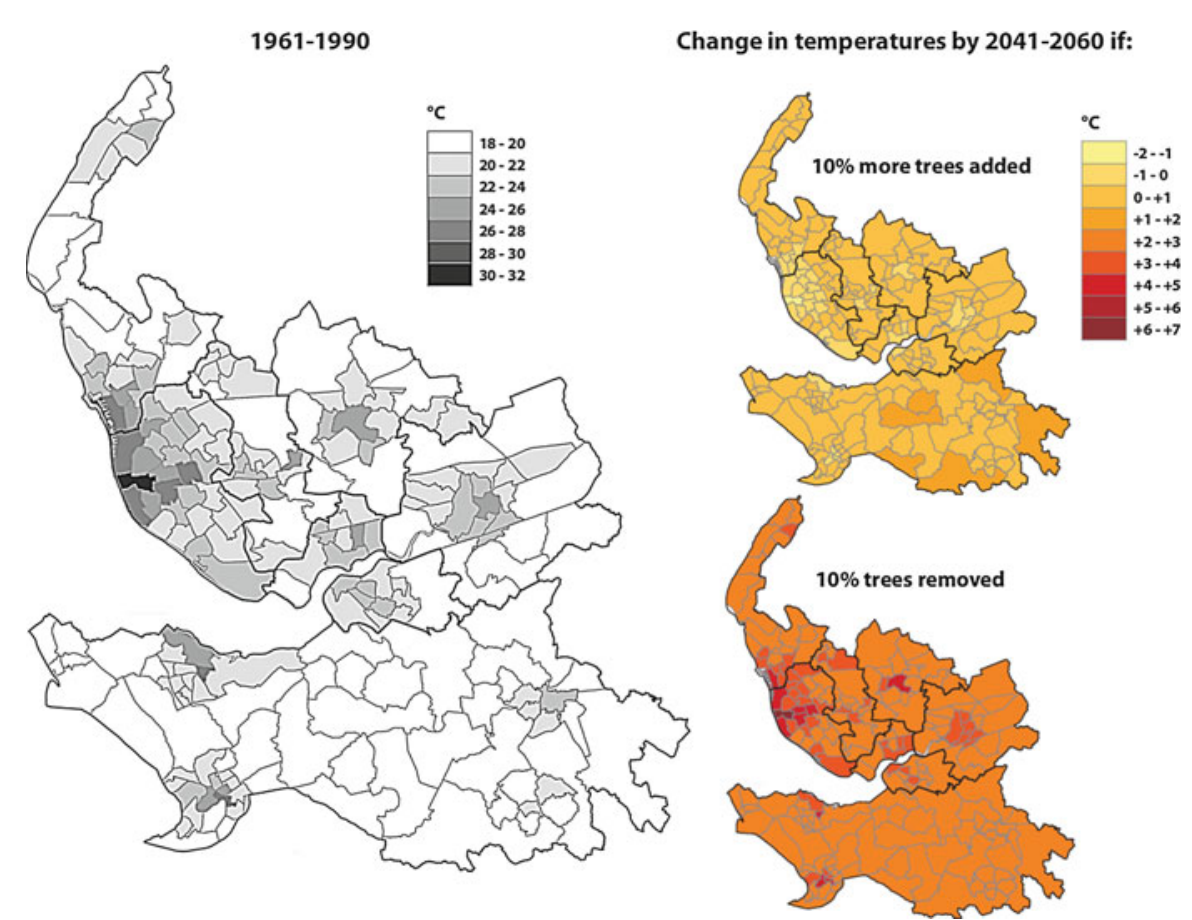

Fig. 7 Maximum surface temperatures on a hot summer's day (98th percentile summers day) (Mapped at the ward level; the 2041-2060 mapping used is for the 2050s high emission scenario, at a $50 \%$ probability level) (C) Crown copyright and database right 2012 Ordnance Survey 100031461)

Liverpool Central, with a maximum surface temperature of $31.7^{\circ} \mathrm{C}$, whereas the coolest ward is Tilston in Cheshire West and Chester at $18.3^{\circ} \mathrm{C}$. There is a surface temperature difference of $13.4{ }^{\circ} \mathrm{C}$ between the hottest and coolest wards. These are also the wards with the lowest and highest green cover (Liverpool Central is $16.7 \%$ green, whereas Tilston is $97.7 \%$ green). By the $2050 \mathrm{~s}$ (at a $50 \%$ probability level), the maximum surface temperature in Liverpool Central increases to $33.9{ }^{\circ} \mathrm{C}$ (2.2 ${ }^{\circ} \mathrm{C}$ hotter than in 1961-1990). Removing green cover from this ward would further exacerbate the situation; if $10 \%$ green cover is removed, then the maximum surface temperature in the $2050 \mathrm{~s}$ would be $38.5^{\circ} \mathrm{C}\left(6.8^{\circ} \mathrm{C}\right.$ hotter than the maximum surface temperature in 1961-1990 with current land cover). However, adding green cover can help to ameliorate the situation; if $10 \%$ green cover is added, then the maximum surface temperature in the 2050 s would be $30.6^{\circ} \mathrm{C}\left(1.1^{\circ} \mathrm{C}\right.$ cooler than the maximum surface temperature in 1961-1990 with current land cover).

The Surface Temperature Tool output was used to support the argument in The Mersey Forest Plan that increased tree planting will provide shade and evaporative cooling that help keep neighborhoods cooler and ensure that towns and cities continue to be healthy, comfortable, and attractive places to live, work, visit, and invest. The results can also be analyzed further by The Mersey Forest team in order to support ongoing activities in delivering the plan.

\section{Conclusions: Lessons Learned and Key Challenges}

The overall aim of the GRaBS project was to enhance local and regional planning policy in respect of climate change adaptation. The Assessment Tool is a useful decision-aiding tool, enabling support of the sharing of knowledge and expertise and helping to build the evidence base available to decision-makers and other stakeholders when developing adaptation plans and strategies. Similarly, 
the STAR Tools can be used to inform climate adaptation plans, green infrastructure plans and strategies, as well as local plans and developments.

Since planning is an integrative data-driven activity to enable effective decisions (Stillwell et al. 1999 cited in Dragicevic and Balram 2004), data availability, quality, and scale are key issues. It is notable that the GRaBS Assessment Tool local partner level tools vary in their comprehensiveness to assess risk and vulnerability based upon the existing spatial data that has been collected. The experience of developing the tools has highlighted the need for a common framework to help identify, collect, distribute, share, and prioritize the data that is required to inform the evidence base and enable a more harmonized approach to spatial planning for adaptation to climate change. This would need to be flexible to enable modification to the user's particular location, specifically in terms of context-specific vulnerability and climatic hazards.

The process of developing the Assessment Tool was invaluable for the GRaBS partners, particularly in helping to build bridges between departments (both internally and externally) during collation of spatial data. A key finding of the project was the need to break down silos between departments in order to gather holistic evidence of the need to act on adaptation. A key lesson is the importance to invest in a collaborative development process with the user, not only because the user can benefit significantly from this process, but also to ensure that resulting tools are not donorcentric, and the end product is provided in an accessible format for the intended user.

Generic challenges have been raised previously in relation to applying a PPGIS approach and are applicable to the GRaBS web-GIS tools - firstly, the cost and time involved in maintaining the currency of tools, including updating the spatial data and information. When developed, the STAR Tools included input data for the complete region of North West England; however, the ongoing data license for the soils input data remained too excessive, and this area was thus reduced to the Mersey Belt area. Further, while the importance of ensuring that the development and maintenance of the Assessment Tool continued beyond the GRaBS project was identified at an early stage, a funding stream through which this could be supported was not secured. The Assessment Tool is hosted as an open-source project at the University of Manchester and is available for use in other case study areas by changing the spatial data and associated metadata - although this requires knowledge of the Google Maps' API and JavaScript programming. Further work in the future could investigate how the Assessment Tool could be easily updated and edited by nonspecialists, to keep it up to speed with changing knowledge and the underlying spatial data.

Secondly, restrictions due to license agreements and confidentiality of sensitive data are a challenge to optimize access to information for the public. Free and open-source tools may conflict with the license agreements of many geospatial datasets (both public and private sectors), constraining the amount of data that can be included in the tool, thereby limiting its effectiveness. The Assessment Tool included a function to add data locally, thereby addressing this issue to some extent. The STAR Tools provide a modeling environment and were designed to enable application in any location, relying more upon user input data and thus minimizing the problem of license restrictions.

A third challenge in developing web-GIS tools is balancing the performance with data resolution. The Assessment Tool achieved fast performance by outputting spatial GIS data into an image format to speed up the map rendering process for the user. However, this approach meant that other useful web-GIS functionalities were restricted, such as changing data classifications or color schemes. Balancing user-friendliness with flexibility was also important in the STAR Tools development. Since the STAR Tools are complex scientific models, it was important that casual users were able to produce their outputs without having to consider or understand the full complexities of the model 
while also allowing more comprehensive users to interact with all underlying model parameters if they so desired.

A fourth challenge is providing enough information for the user to be able to apply the tool and interpret the data or output effectively. Detailed notes and guidance materials (including storylines) provided for the GRaBS Tools go some way to aiding this issue, but training events may also be beneficial, both to enhance understanding of the tools and ensure greater application. A more recent review of tools by Climate UK (2012), which included review of the Assessment Tool and STAR Tools, suggested that there is little demand from UK stakeholders for new tools but more demand in terms of awareness raising and use of existing tools, including clear guidance on how the tools can be best applied. As the STAR Tools were released toward the end of the GRaBS project, buy-in from GRaBS partners was limited, and encouraging stakeholders to use the tool is challenging. Despite efforts to publicize the STAR Tools, usage remains low relative to the investment in developing the tools. Creation of a "toolbox of tools" by national and cross-sectoral organizations would therefore be useful to signpost stakeholders to the tools.

A final challenge for web-GIS tools is the fast pace of change in technology. When the Assessment Tool was envisaged, Google Maps was the only viable mapping Application Programming Interface (API). Since then, a number of other APIs, including Bing and OS OpenSpace have arisen, with functionality advancing at an unchecked rate. Additionally, post-GRaBS, a significant change in Web Map Services (WMS) in the UK in particular has occurred, with national organizations shifting to deliver their spatial data via WMS. Linking to the spatial data via WMS means there is no need to keep a local copy of the data that becomes outdated. While challenging, these fast changes are also very encouraging for the development of web-GIS tools and enhancing public participation in planning.

In terms of the future development of tools for climate change adaptation planning in cities, it is clear that the Public Participatory ("PP" in PPGIS) element could be advanced much further. Additional functions for the Assessment Tool such as push pins (to enable highlighting of locations of interest) and comment boxes could be applied to enable a more interactive facility, which could be extremely effective when utilizing the tool for community participation events. Gathering of user experiences and evidence could be particularly beneficial for climate change adaptation planning. For example, crowdsourcing local flooding evidence may be very useful to verify modeled flooding hazard outputs and official flood records utilizing the geo-referencing capabilities within social media applications.

Finally, Climate UK (2012) highlights that the greatest demand from existing tools is to help with prioritizing clear next steps and actions. Many tools, including the Assessment Tool and STAR Tools, are very effective in their ability to raise awareness about climate impacts and the need for adaptation responses, though they do not necessarily aid prioritization of risks and opportunities. This is an area that should be considered in future developments.

\section{Acknowledgments}

The GRaBS project was funded under Interreg IVC, project number 0108R1. The authors would like to thank the GRaBS project partners in addition to Dr Stephen Lynch, from Manchester Metropolitan University, for assistance with the mathematics of the ST Tool. The Mersey Forest Plan was part funded by the EU Interreg IVB GIFT-T! (Green Infrastructure For Tomorrow - Together!) project. The GRaBS Tools build on research from the EPSRC-funded project Adaptation Strategies for Climate Change in the Urban Environment (ASCCUE), EPSRC GR/S19233/01. 


\section{References}

Bowler DE, Buyung-Ali L, Knight TM, Pullin AS (2010) Urban greening to cooltowns and cities: a systematic review of the evidence. Landsc Urban Plan 97:1477-155

Carter J, Kazmierczak A, Cavan G (2010) Linking the GRaBS assessment tool and adaptation action plans. A report for the GRaBS partnership. University of Manchester

Cavan G, Kingston R (2012) Development of a climate change risk and vulnerability assessment tool for urban areas. Int J Disaster Resilience Built Environ 3(3):253-269

Checkland PB (1999) Systems thinking, systems practice. Wiley, Chichester

Climate UK (2012) Review of adaptation tools, sustainability West Midlands. Available from: http:// media.climateuk.net/sites/default/files/Tools_Review.pdf

Crichton D (2001) The implications of climate change for the insurance industry. Building Research Establishment, Watford

Cockburn A (2000) Writing effective use cases. Addison-Wesley, Boston

Department for Communities and Local Government (2012) National planning policy framework. Available from: https:/www.gov.uk/government/uploads/system/uploads/attachment_data/file/ 6077/2116950.pdf

Dragicevic S (2004) The potential of web-based GIS. J Geogr Syst 6:79-81

Dragicevic S, Balram S (2004) A Web GIS collaborative framework to structure and manage distributed planning processes. J Geogr Syst 6:133-153

ESPACE (2008) Climate change impacts and spatial planning decision-support guidance. Available at http://www.espace-project.org/publications/Extension\%20Outputs/EA/Espace\%20Final_Guidance Finalv5.pdf

Garg A, Rana A, Shukla PR, Kapshe M, Azad M, (2007) Handbook of current and next generation vulnerability and adaptation assessment tools. Paper 8 BASIC project. Available from: http:// www.basic-project.net/

Gill SE (2006) Climate change and urban greenspace. Unpublished PhD thesis, School of Environment and Development, University of Manchester

Gill SE, Handley JF, Ennos AR, Pauleit S (2007) Adapting cities for climate change: the role of the green infrastructure. Built Environ 33:115-133

IPCC (2007) Climate Change 2007, The physical science basis: summary for policy makers. Contribution of the Working Group 1 to the Fourth Assessment Report of the Intergovernmental Panel on Climate Change, Cambridge, Cambridge University Press

IPCC (2013) In: Stocker TF, Qin D, Plattner GK, Tignor M, Allen SK, Boschung J, Nauels A, Xia Y, Bex V, Midgeley PM (eds) Climate change 2013: the physical science basis. Contribution of working group I to the fifth assessment report of the intergovernmental panel on climate change. Cambridge University Press, Cambridge/New York, p 1535

IPCC (2014) Summary for policymakers. In: Field CB, Barros VR, Dokken DJ, Mach KJ, Mastrandrea MD, Bilir TE, Chatterjee M, Ebi KL, Estrada YO, Genova RC, Girma B, Kissel ES, Levy AN, MacCracken S, Mastrandrea PR, White LL (eds) Climate change 2014: impacts, adaptation and vulnerability. Part A: global and sectoral aspects. Contribution of working group II to the fifth assessment report of the intergovernmental panel on climate change. Cambridge University Press, Cambridge/New York, pp 1-32

Kazmierczak A, Carter J (2010) Adaptation to climate change using green and blue infrastructure. A database of case studies. Interreg IVC Green and blue space adaptation for urban areas and eco towns (GRaBS) project. Available from: http://www.grabs-eu.org/membersArea/files/ Database_Final_no_hyperlinks.pdf 
Kingston R (2007) Public participation in local policy decision-making: the role of web-based mapping. Cartogr J 44(2):138-144

Kingston R, Carver S, Evans A, Turton I (2000) Web-based public participation geographical information systems: an aid to local environmental decision-making. Comput Environ Urban Syst 24(2):109-125

Lindley SJ, Handley JF, Theuray N, Peet E, McEvoy D (2006) Adaptation strategies for climate change in the urban environment - assessing climate change related risk in UK urban areas. J Risk Res 9(5):543-568

Lindley SJ, Handley JF, McEvoy D, Peet E, Theuray N (2007) The role of spatial risk assessment in the context of planning for adaptation in UK urban areas. J Built Environ 33(1):46-69

London Borough of Sutton (2011) Borough climate change adaptation strategy. Available at: http:// www.grabs-eu.org/downloads/Sutton\%20Climate\%20Change\%20adaptation $\% 20$ strategy $\%$ 20march\%202011.pdf

London Borough of Sutton (2013) Community map. Available from: http://gis.sutton.gov.uk/ CommunityMap/Default.aspx

Peng Z (2001) Internet GIS for public participation. Environ Plan B Plan Des 28:889-905

Provincia di Genova (2011) Climate change adaptation action plan. Executive summary. Available at: http://www.grabs-eu.org/downloads/Province\%20of\%20Genoa\%20AAP_Executive\%20summary.pdf

Provincia di Genova (2013) ADAPTO adaptation action planning toolkit. Available from: http:// cartogis.provincia.genova.it/cartogis/grabs/adapto.htm

Scholze M, Wahl M (eds) (2009) Report of the international workshop on mainstreaming adaptation to climate change guidance and tools. In: Workshop held at GTZ House Berlin, Potsdam Square May 28th - 30th, 2009 organised by DFID - GTZ - USAID - World Bank. Deutsche Gesellschaft für Technische Zusammenarbeit (GTZ) GmbH Climate Protection Programme for Developing Countries, Eschborn, July 2009

SRS (1972) Soil conservation service national engineering handbook - Section 4: hydrology. United States Department of Agriculture, Soil Conservation Service, Washington, DC

Stillwell JCH, Geertman S, Openshaw S (1999) Developments in geographical information and planning. In: Openshaw S (ed) Geographical information and planning. Springer, Berlin and New York, pp 3-22

Stratus Consulting Inc (1999) Compendium of decision tools to evaluate strategies for adaptation to climate change. Prepared for: UNFCCC Secretariat Bonn, Germany, May 1999. Available from: http://www.atmosfera.unam.mx/cclimat/Taller_CCA_INE_dic08/UNFCCC_adaptation_compend ium.pdf

Southampton City Council.(2011) Low carbon city 2011-2020. Part 3: the delivery plan. Available at: http://www.grabs-eu.org/downloads/Part\%203\%20-\%20The\%20Delivery\%20Plan $\% 202011 \% 20-\% 202014 . p d f$

The Mersey Forest (1994) The Mersey forest plan, Merseyside, UK

The Mersey Forest (2014) More from trees: the Mersey forest plan. Available from: www. merseyforest.org.uk/plan

Tso CP, Chan BK, Hashim MA (1991) Analytical solutions to the near-neutral atmospheric surface energy balance with and without heat storage for urban climatological studies. J Appl Meteorol 30(4):413-424

Tso CP, Chan BK, Hashim MA (1990) An improvement to the basic energy balance model for urban thermal analysis. Energy Build 14(2):143-152

UKCIP (2008) The UKCIP adaptation wizard v 2.0. UKCIP, Oxford 
Whitford V, Ennos AR, Handley JF (2001) "City form and natural process" - indicators for the ecological performance of urban areas and their application to Merseyside, UK. Landsc Urban Plan 57(2):91-103

Willows R, Connell R (2003) Climate adaptation: risk, uncertainty and decision-making. UKCIP technical report, Oxford 